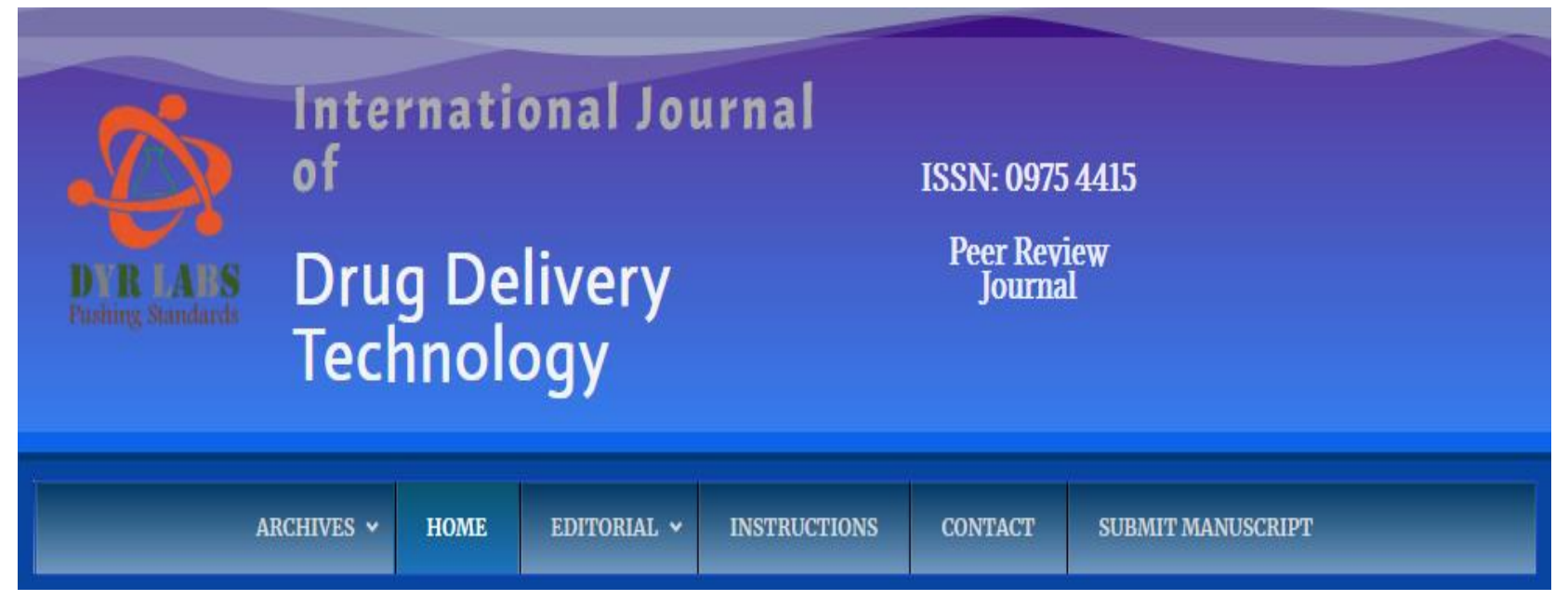


EDITOR IN CHIEF

Prof. Dina Nath Mishra

Professor and Head of Pharmaceutics, Department of Pharmaceutical Sciences,

Guru Jambheshwar University of Science and Technology, INDIA

Board Members

Dr. Somnath Singh

Creighton University,Omaha, USA

Dr. Tathagata Dutta

University of Queensland, Brisbane, AUSTRALIA

Dr. Ashish Suttee

Lovely Professional University, Phagwara, INDIA

Dr. Kalpesh Gaur

Geetanjali College of Pharmaceutical Studies, Udaipur, INDIA

Dr. Vishal Gupta

Director, Research \& Developement Covidien, USA

Dr. Chandan M. Thomas

Department of Pharmaceutical Sciences, Lake Erie College of Osteopathic Medicine and

School of Pharmacy 5000 Lakewood Ranch Blvd, Bradenton, Florida-34211

Prof. Kamla Pathak

Rajiv Academy of Pharmacy, Mathura, INDIA

Prof. V. R. Sinha

Panjab University, Chandigarh, INDIA

Prof. Pramil Tiwari

National Institute of Pharamceutical Education and Research (NIPER), Mohali, INDIA

Prof. Arun Nanda

Faculty of Pharm. Sciences, Maharshi.Dayananad.University, Rohtak, INDIA

Prof. O.P.Katare

Panjab University, Chandigarh, INDIA

Dr. Amit Bhatia

Lovely Professional University, Punjab, INDIA

Dr. Anil Philip

Rajiv Academy Academy of Pharamacy, Mathura, INDIA

Dr. Dinesh Kaushik

Hindu College of Pharamcy, Sonepat, INDIA. 
Dr. Munish Ahuja

Dept. of Pharm. Sciences, Guru Jambheshwar University of Science and Technology, Hisar, INDIA

Dr. Sanju Nanda

Dept. of Pharm. Sciences,M.D.University, Rohtak, INDIA

Dr. Rakesh P. Patel

S.K. Patel College of Pharm. Edu. \& Res., Ganpat University, Gujarat, INDIA.

Dr. Bhaskar Mazumder

Dept. of Pharmaceutical Sciences, Dibrugarh University, Dibrugarh, Assam, INDIA.

Dr. Kalpana Nagpal

Apeejay Satya University, Sohna, Gurgaon, Haryana, INDIA

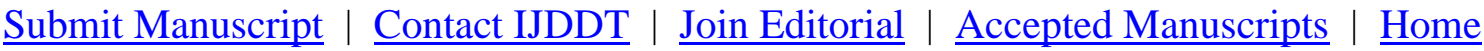


Home > Archives > Vol 8, No 3 (2018)

\section{Vol 8, No 3 (2018)}

International Journal of Drug Delivery Technology

\section{Table of Contents}

\section{International Journal of Drug Delivery Technology}

Design of Nanostructured Lipid Carriers Ubiquinone-10 for Transdermal Treatment

M Fatchur Rochman, Isnaeni ., Esti Hendradi

Novel First Order Derivative UV Spectrophotometric Method for the Determination of Glimepiride in Solid Dosage Forms

Santosh Karajgi , Sunayana Mali, Ramaling Kotnal

Formulation and Evaluation of Tramadol Hydrochloride Sustained Release Matrix Tablets

B Sai Adithya, Gulshan Mohammad, Rama Rao Nadendla

Development and In Vitro Characterization of Solid Lipid Nanoparticles(SLN) Containing Methotrexate And Doxycycline

Vijaya R, Ram Kishan K R

Effect of Lipid Composition on Nanostructured Lipid Carrier (NLC) on Ubiquinone Effectiveness as an Antiaging Cosmetics

Tamara Gusti Ebtavanny, Widji Soeratri, Noorma Rosita

ISSN: 0975-4415

Disclimer: Scopus and Crossref are registered trademark of respective companies. This journal is member of Crossref. 


\title{
Effect of Lipid Composition on Nanostructured Lipid Carrier (NLC) on Ubiquinone Effectiveness as an Anti-aging Cosmetics
}

\author{
Tamara Gusti Ebtavanny ${ }^{1}$; Widji Soeratri ${ }^{1}$, Noorma Rosita ${ }^{1 *}$ \\ ${ }^{I}$ Department of Phamaceutics, Faculty of Pharmacy. Universitas Airlangga \\ Jl. Dharmawangsa Dalam, Surabaya, Indonesia.
}

Received: $7^{\text {th }}$ Dec, 17; Revised: $4^{\text {th }}$ Sep, 18, Accepted: $12^{\text {th }}$ Sep, 18; Available Online: $25^{\text {th }}$ Sep, 2018

\begin{abstract}
The purpose of this research is to determine the optimum composition of solid lipid and liquid lipid in order to increase the penetration and effectiveness of Q10 as antioxidant in anti-aging cosmetics. Solid lipid and liquid lipid used in this study were cetyl palmitate and caprylic, which were combined to four (4) different ratios, namely 10:0;9:1; 7:3 and 5:5. NLC Q10 in this study was produced by high shear homogenization method at $3400 \mathrm{rpm}$ for 5 cycles and at 24000 for 1 cycle. The fourth formula was evaluated in term of characteristics, penetration and effectiveness. From the $\mathrm{pH}$ test, it was known that all formulas met the skin pH range (4.0-6.0). For the particle size test, all formulas (NLC 1 - NLC 4) were in the range from 269.13 to $354.77 \mathrm{~nm}$ with NLC 3 (7: 3 ) had the smallest particle size. The results of viscosity and surface tension test were also consistent with the theory, where the addition of liquid lipid reduced viscosity and surface tension of the system. The entrapment efficiency (EE) demonstrated the EE of NLC 1: $22.24 \%$; NLC 2: $24.71 \%$; NLC 3: $58.21 \%$ and NLC 4 : $36.94 \%$. The penetration test showed all systems were able to penetrate the dermis layer at the $5^{\text {th }}$ hour. NLC $3(7: 3)$ had more rapid onset, while the NLC Q10 with the ratio of lipid 9:1, had slower onset of action but can penetrate farther than the other NLC Q10 system. The result of Q10 effectiveness test showed NLC 2 (9:1) has lowest total macrophage (23.33) and very dense collagen observation (score : 4). From this research, it can be concluded that NLC $2(9: 1)$ had the most optimal lipid composition to increase the penetration and effectiveness of Q10 as an antioxidant in anti-aging cosmetics.
\end{abstract}

Keywords: Ubiquinone, NLC, lipid composition, antioxidant, anti-aging

\section{INTRODUCTION}

Aging is defined as intrinsic inability progressive process of the body to maintain and repair itself to work effectively $^{1,2}$. Aging occur due to excessive UV exposure also called photoaging. To cope with oxidative stress and cell damage due to UV exposure, one of treatment used is antioxidants. Antioxidant that naturally present in body is Isopropyl palmitate, vitamin $\mathrm{C}$ and Ubiquinone $(\mathrm{Q} 10)^{3}$. Ubiquinone $(\mathrm{Q} 10)$ is one of the antioxidants that can prevent Premature aging caused by chronic UV exposure by inhibiting the formation of ROS, activation of AP-1 and $\mathrm{IL}-1 \alpha^{4,5}$. Nowadays, Q10 has been developed and used because has many advantages, such as increases the formation of elastin in fibroblasts; increases the expression of type III and IV collagen and lowers the depth of wrinkles around eyes after 6 months of use ${ }^{5}$. However, Q10 also has many weakness, such as very lipophilic, low solubility in water $(<\mathrm{lppb})$, and had large molecular weight. It causes difficulty for Q10 to penetrate into Stratum Corneum. However, Q10 is unstable and easily degraded when exposed to light. It is necessary to have delivery system that can improve the Q10 stability, to extend the effective time and deliver Q10 to penetrate the stratum corneum (SC) as well as ability to achieve controlled release ${ }^{6}$. One of delivery systems which widely developed is the second generation lipid nanoparticles, called NLC. NLC is developed from SLN by adding liquid lipid into solid lipid. The addition of this liquid lipid will change the crystal lattice structure of solid lipid from ordered into unordered structure, so there will be more space for the active material ${ }^{7}$. This crystal structure change will affect the surface tension, viscosity solubility and stability of active material. Such as, NLC system can improve the stability of antioxidants of tomato extract ${ }^{8}$. The NLC system not only increases the stability of the compound, but also has good skin adhesion and bioavailability. When the particle adheres to the skin surface, it will accumulate to generate packets action effect, which reduces water loss in the skin surface and increases skin hydration in order to protect the skin ${ }^{14}$. From the experiments conducted by Malik et al in 2018, suggested that NLCs could serve as a promising carrier for site specific targeting with better skin retention abilities ${ }^{17}$. One of components that affect the NLC effectiveness as the delivery system of active ingredient is lipid composition ${ }^{9}$. Lipids used in this study is cetyl palmitate (solid lipid) and caprylic (liquid lipids), which are combined into four (4) different ratios. Four NLC Q10 formulas made in this study is the NLC1 (NLC Q10 with ratio of solid lipid: liquid lipid = 10: 0); NLC 2 (NLC Q10 with ratio of solid lipid: liquid lipid =9: 1); NLC 3 (NLC Q10 with ratio of solid lipid: liquid lipid $=7: 3$ ); NLC 4 
Table 1: Formula of NLC Q10 (\%w/w)

\begin{tabular}{llcccc}
\hline Material & \multicolumn{1}{c}{ Function } & \multicolumn{3}{c}{ Concentration (\%) } \\
\cline { 2 - 6 } & & NLC 1 & NLC 2 & NLC 3 & NLC 4 \\
\hline Q10 & Active Ingredient & 1 & 1 & 1 & 1 \\
Cetyl palmitat & Solid lipid & 14 & 12,6 & 9,8 & 7 \\
Caprylic & Liquid Lipid & - & 1,4 & 4,2 & 7 \\
Tween 80 & Surfactant & 10 & 10 & 10 & 10 \\
Span 80 & Surfactant & 10 & 10 & 10 & 10 \\
Propylene Glycol & Co-Surfactant & 10 & 10 & 10 & 10 \\
Acetate buffer pH & Water phase & 100 & 100 & 100 & 100 \\
$(4.2 \pm 0.2)$ ad & & & & & \\
\hline
\end{tabular}

Table 2: Examination results of viscosity and surface tension from NLC Q10.

\begin{tabular}{ccc}
\hline Formula & Viscosity & Surface Tension \\
\hline NLC 1 & 9775.00 & $7.61 \times 10-3$ \\
NLC 2 & 6808.00 & $5.66 \times 10-3$ \\
NLC 3 & 186.70 & $4.21 \times 10-3$ \\
NLC 4 & 137.50 & $4.65 \times 10-3$ \\
\hline
\end{tabular}

Note:

NLC 1: NLC Q10 Formula with Solid Lipid : Liquid Lipid ratio $=10: 0$

NLC 2: NLC Q10 Formula with Solid Lipid : Liquid Lipid ratio $=9: 1$

NLC 3: NLC Q10 Formula with Solid Lipid : Liquid Lipid ratio $=7: 3$

NLC 4: NLC Q10 Formula with Solid Lipid : Liquid Lipid ratio $=5: 5$

(NLC Q10 with ratio of solid lipid: liquid lipid $=5: 5$ ) The four formulas were tested in terms of characteristics, penetration and in-vivo effectiveness. The physical characteristics test of the study included $\mathrm{pH}$ test, particle size, polidispersity index, viscosity, surface tension and particle morphology test. Penetration test was performed by the in-vivo method using Wistar rat skin membrane. After application of $50 \mathrm{mg}$ sample, the skin was then taken on the $3^{\text {rd }}, 5^{\text {th }}$ and $7^{\text {th }}$ hour, and then observed using floresense microscope. The effectiveness test of Q10 as antiaging in this study has passed from ethical feasibility test from Airlangga University and included three aspects, namely the amount of macrophages (AM), amount of fibroblasts (AF) and amount of collagen (AK) which counted as qualitative scoring system

\section{METHOD}

\section{Instruments}

The instruments used in this research were: Differential Scanning Calorymetry (DSC), X-Ray Powder Diffraction (Philips X'Pert, Netherland), Double Beam Spektrofotometer Shimadzu UV-1800, Particle Analyzer Delsa $^{\mathrm{TM}}$ Nano Submicron Particle Size, Ultra Turrax IKA® T25 Digital High Shear Homogenizer, Scanning Electron Microscope (SEM) JEOL JSM 840, Magnetic Stirer, Hotplate Dragon Lab MS H-Pro, pH meter Schott Glass Mainz tipe CG 842, viskosimeter Cone and Plate (CPE 41), Fluorescence Microscopy (Olympus FX-1000), Cryostat, sentrifuge (Hettich Rotofix 32), analytical balance of CHYO JP-160, thermometer, complete rat cage
Table 3: The EE test results of NLC formulas.

\begin{tabular}{ccc}
\hline Formula & EE average $(\%) \pm$ SD & KV \\
\hline NLC 1 & $22.24 \pm 1.50$ & 6.76 \\
NLC 2 & $24.71 \pm 1.77$ & 7.17 \\
NLC 3 & $58.21 \pm 0.09$ & 0.16 \\
NLC 4 & $36.94 \pm 0.46$ & 1.25 \\
\hline
\end{tabular}

(with food and drink), Fixation board, Optilab, LC Optimal camera, broadband ultraviolet B lamp

\section{MATERIALS}

The materials used in this research if did not state otherwise, were in pharmaceutical grade purity. The materials used in this research were Ubiquinone (Q10), Cetyl palmitate, caprylic, Tween 80 , Span 80 , Propylene Glycol and acetate buffer. Acetate buffer with pH $4.2 \pm 0.2$ is made of glacial acetic acid and sodium acetate with pro analysis quality.

Preparation Of NLC Q10

NLC Q10 was made by the High Shear Homogenizaton method. The lipid phase and the aqueous phase were made with a high shear homogenizer Ultra-turax with speed of $3400 \mathrm{rpm}$ for 1 minute at temperature $\left(50^{\circ} \pm 5^{\circ} \mathrm{C}\right)$ for 3 cycles each. The lipid phase and water phase were then mixed with high shear homogenizer Ultra-turax with speed of $24000 \mathrm{rpm}$ in 3 minutes. Cooling phase then be performed at speed of $500 \mathrm{rpm}$ until reached room temperature.

Physical Charateristic Test of NLC Q10

Physical characterization test included organoleptic, $\mathrm{pH}$, viscosity, particle size and polidipersity index, particle morphology, determination of diffraction pattern and regularity of crystal structure and entrappment efficiency test

Particle Size and Polydipersity Index Test

The average particle size and particle size distribution test of sample was performed with Delsa ${ }^{\mathrm{TM}}$ Nano Submicron Particle Size Analysis

Particle Morphology Test

particles morphology test was performed using Scanning Electron Microscope (SEM). Magnification used was 5000x.

Determination of Diffraction Pattern and Crystal Structure Regularity:

$\mathrm{X}$-ray diffraction analysis of samples powder was done at room temperature by using X-Ray Powder Diffraction (XRPD) 


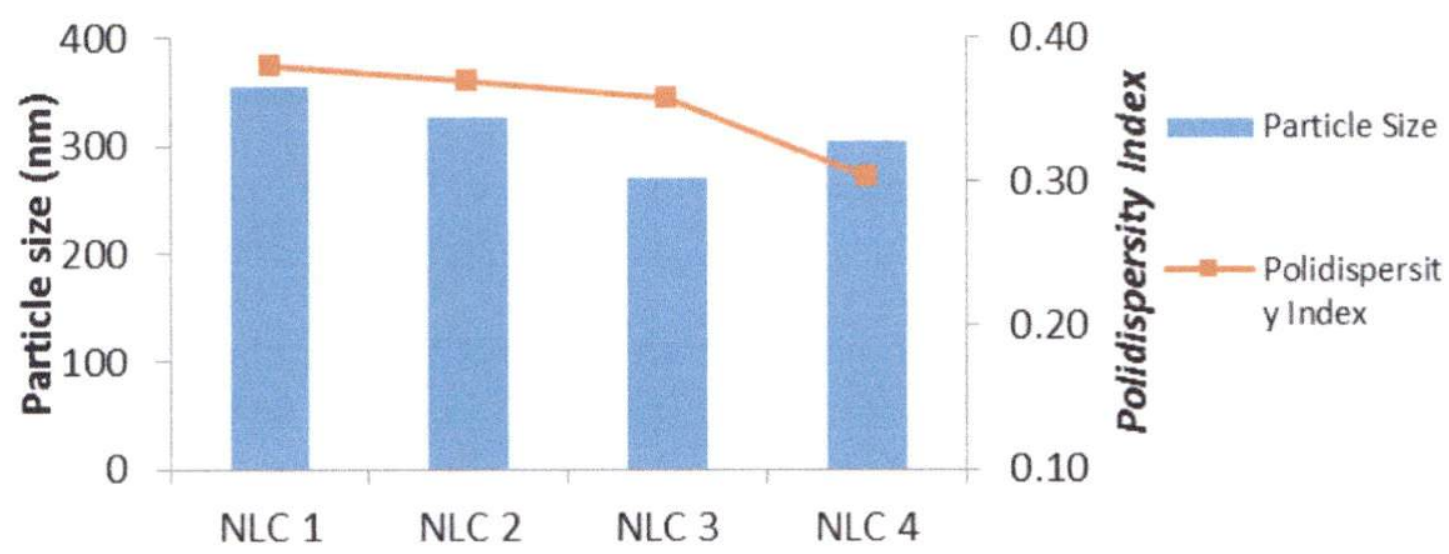

Figure 1: Graph of particle size and polidispersity index(PI) of NLC Q10.

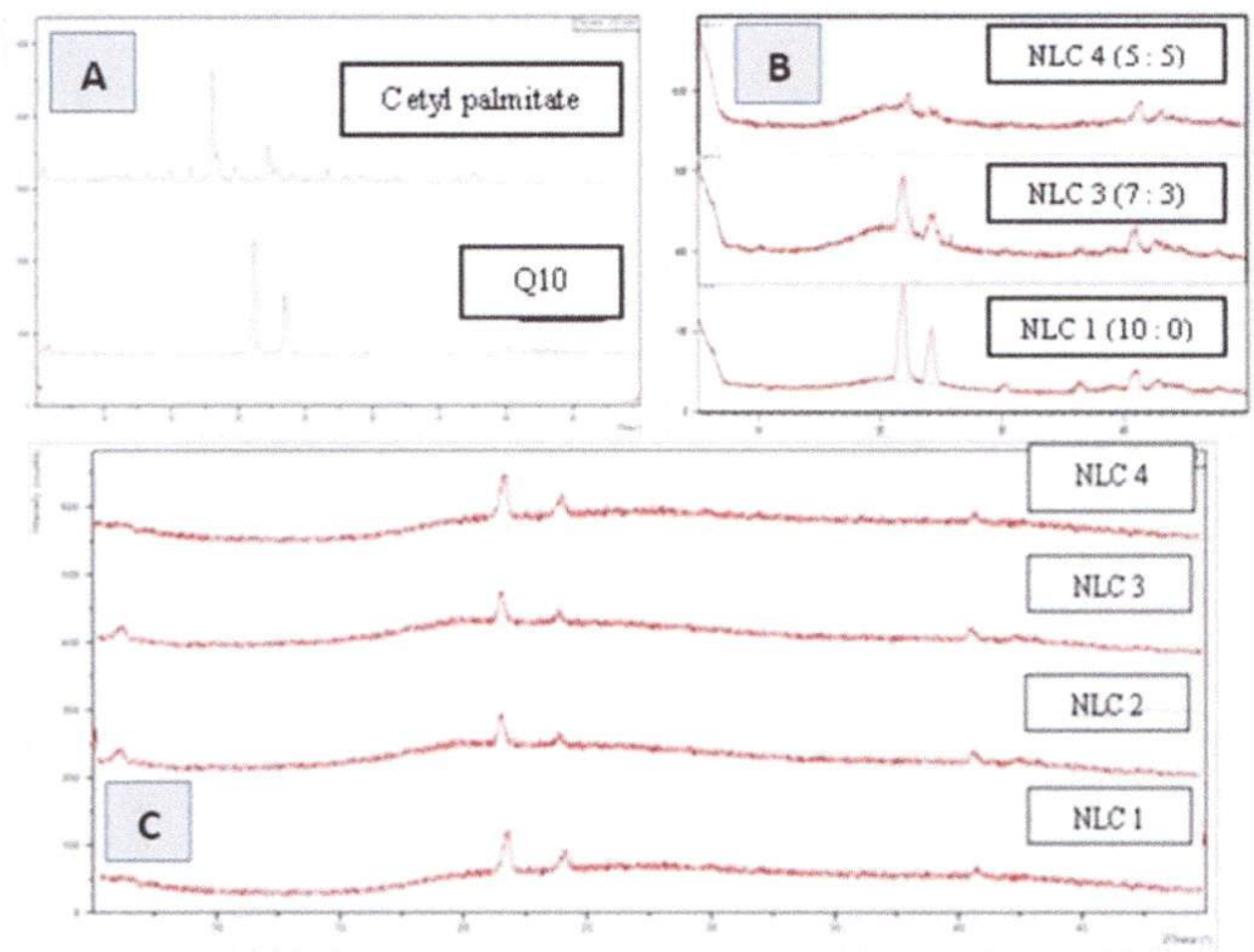

Figure 2: Diffraction Patterns and Regularity of Crystal Structure: A : Single material, Q10 dan cetyl palmitate (at 05000 intensity); B : lipid mixture of solid and liquid lipid at various lipid compositions (at 0-1600 intensity); C : NLC Q10 on various lipid compositions (at $0-600$ intensity).

\section{Entrappment Efficiency Test}

Entrappment efficiency eveluation was performed using centrifugation method at $1500 \mathrm{rpm}$ for 15 minutes. \% EE was calculated from the initial concentration of Q10 subtracted with the untrapped Q10 content divided by initial content of Q10

$$
\mathrm{EP}(\%)=[(\mathrm{Ct}-\mathrm{Cf}) / \mathrm{Ct}] \times 100 \%
$$

\section{Note :}

$\mathrm{Ct}$ : Initial concentration of Q10 in NLC

Cf : Untrapped concentration of Q10

In-vivo Penetration Test

The research object used in this penetration tests in NLC system was Wistar rats what met the inclusion criteria (healthy; 8-10 weeks age; weight of 100-250 grams) and did not meet the exclusion criteria (there is concomitant skin diseases and prevent bleeding in mouse skin). The sample size used was 36 rats, which consisted of 12 test groups in the observations of 3,5 and 7 hours. Rats is anesthetized with ketamine, and then the abdomen hairs were cleaned using mechanical hair clipper. $50 \mathrm{mg}$ test sample which have been given fluorescent dye (rhodamine) then applied to the rat skin. At each observation hour $\left(3^{\text {rd }}, 5^{\text {th }}\right.$ and $7^{\text {th }}$ hour $)$ the skin was cut using frozen microtome in $5 \mu \mathrm{m}$ thickness. Skin sample was then observed with microscope fluorescent at 70 times magnification.

Anti-aging In Vivo Activity Test 

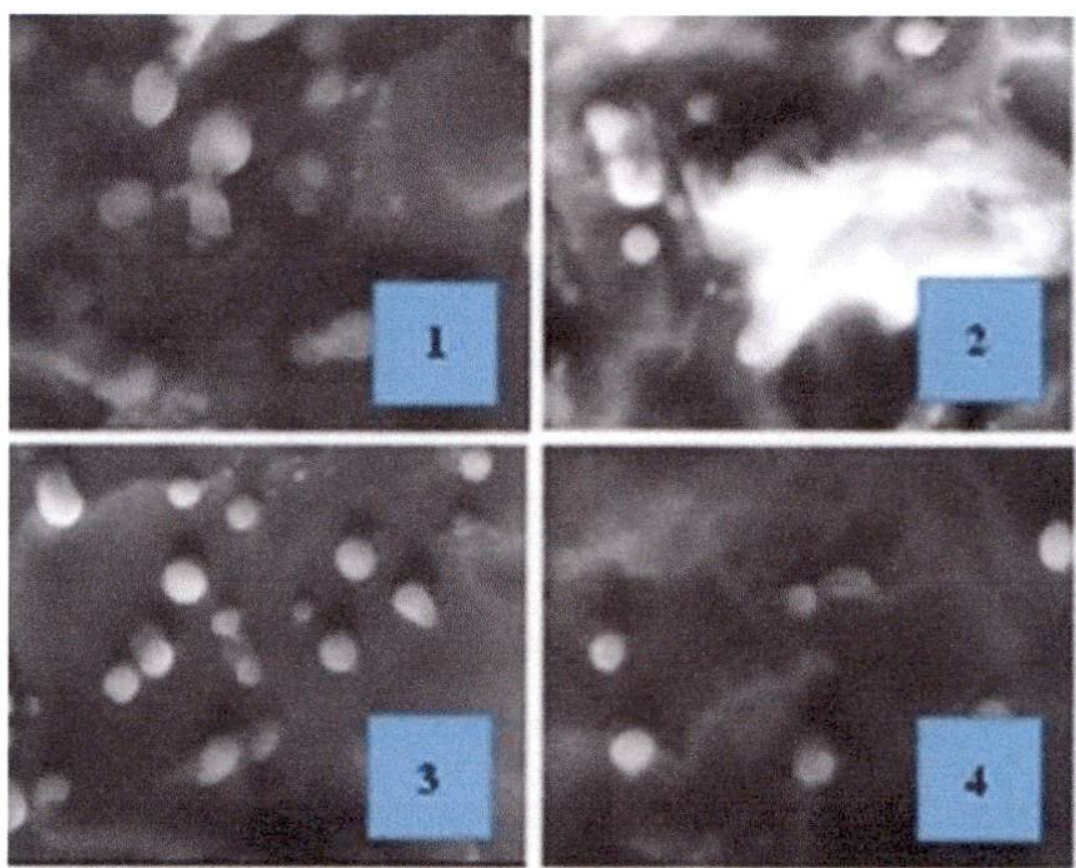

Figure 3: NLC Q10 particle morphologies at various lipid compositions.

The research object used in this anti-aging effectiveness test has the same citeria with object which was used in penetration test. The sample size used was 24 rats, which divided into six test groups, four groups of test samples and two control groups. Rat back were shaved exposed to UV light at dose of $840 \mathrm{~mJ} / \mathrm{cm}^{2}$. Exposure was three times a day for 5 days until total dose reached $840 \mathrm{~mJ} / \mathrm{cm}^{2}$. Four (4) different test samples were applied two times for each treatment, which was 20 minutes before exposure (to allow time for topicals absorption into the skin) and 4 hours after exposure (ROS formation started 4 hours after exposure). On day 5 , the skin was taken and then analyzed by optical microscopy to obtain total amount of macrophages, fibroblast and collagen.

\section{RESULTS AND DISCUSSION}

Organoleptic Examination

The result of the organoleptic test showed that all formulas have yellow color, the distinctive smell of acetate buffer and semisolid consistency. NLC 3 and NLC 4 have the less semisolid consistency because of the more liquid lipid addition on both formulas. However, blends with liquid lipid $>10 \%$ exhibited miscibility issues. This could be attributed to the disruption of ordered arrangement of solid lipid and expulsion of oil from the lipid matrix at higher liquid lipid concentration ${ }^{17,18}$

pH Examination

From the $\mathrm{pH}$ examination results at various lipid compositions can be seen that $\mathrm{pH}$ of all NLC samples have fulfilled skin pH range of 4.00 to 6.00 .

Viscosity and Surface Tension Examination

Results of viscosity and surface tension tests from all NLC formulas were shown in the following table.

From Table 2, it can be seen that with the increasing concentration of the liquid lipid, the system viscosity and system surface tension reduced. The addition of liquid lipid reduced the system surface tension, where it also reduced the system viscosity ${ }^{10}$.

Particle Size and polidispersity index Examination

The examination results of all NLC formulas can be seen in figure 1From the graph it can be seen that size of all NLC Q10 formulas were below $400 \mathrm{~nm}$, The particle size was slightly increased by encapsulation of molecules (Q10) compared to the drug-free $\mathrm{NLCs}^{24}$. Polidispersity index of NLC Q10 can also be seen below 0,4 . This result indicating a monodisperse, narrow and homogeneous size distribution because PI was below $0.3^{19,24}$. In summary, by adding liquid lipid concentration, the particle size and system PI were smaller, which means that the formed system become more homogenous ${ }^{9,10}$. Based on the ANOVA statistical analysis resultas, system particle size examination of NLC Q10 obtained p-value (sig) lower than 0.05 . It showed significant difference of particle size between all NLC formulas at various lipid compositions. Whereas anova statistical analysis results of polidispersity index of NLC Q10 system obtained that p-value (sig) was greater than 0.05 . This showed that no significant differences of polidispersity index between NLC formula at various lipid compositions.

Crystallinity Test

The diffraction patterns and regularity test results of crystal structure over angles range $2 \theta 5^{\circ}-50^{\circ} \mathrm{can}$ be seen in the ffigure.

From figure 2 (B), it can be seen that with the increasing concentration of liquid lipid, the diffraction intensity was decreasing. This is due to the more liquid lipid addition the more changes of internal crystalline structure, where it able to increase drug loading ${ }^{11,12}$. From figure $2(\mathrm{C})$, it can be seen that the absorption peaks of cetyl palmitate in NLC system was still visible, although the intensity was not as high as in single material diffraction. This showed that Q10 were completely dissolved and encapsulated in the lipid 
Result of penetration depth test at $3^{\text {rd }}$ hour
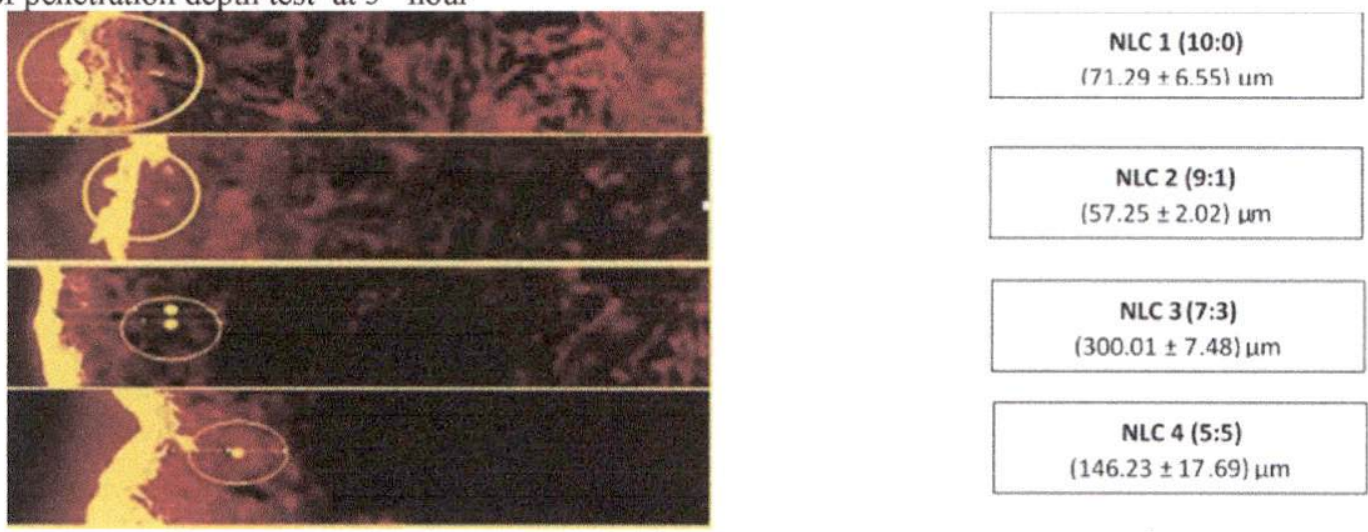

Figure 4: NLC Q10 penetration depth at various lipid compositions at $3^{\text {rd }}$ hour

Result of penetration depth test at $5^{\text {th }}$ hour

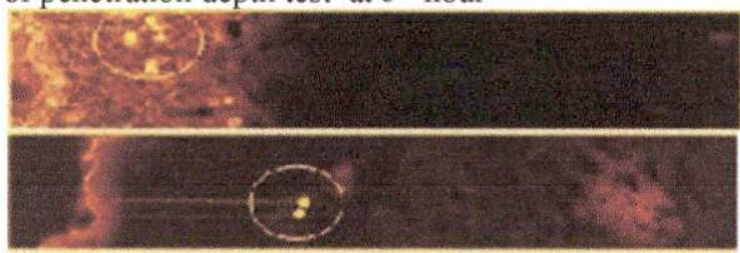

\begin{tabular}{|c|}
\hline $\begin{array}{c}\text { NLC 1 }(10: 0) \\
(185, .01 \pm 14.76) \mu \mathrm{m}\end{array}$ \\
\hline $\begin{array}{c}\text { NLC 2 (9:1) } \\
(357.33 \pm 7.36) \mu \mathrm{m}\end{array}$ \\
\hline $\begin{array}{c}\text { NLC 3 }(7: 3) \\
(345,33 \pm 13,27) \mu \mathrm{m}\end{array}$ \\
\hline $\begin{array}{c}\text { NLC 4 }(5: 5) \\
(272,33 \pm 43,28) \mu \mathrm{m}\end{array}$ \\
\hline
\end{tabular}

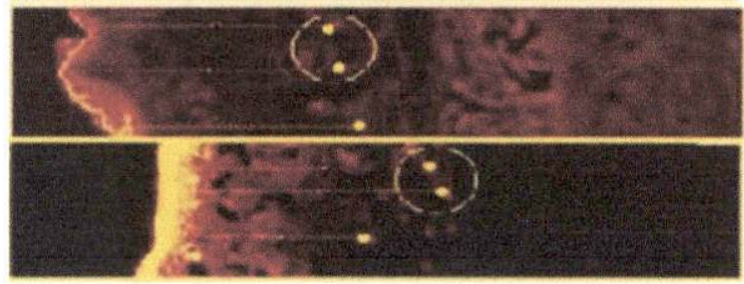

$(272,33 \pm 43,28) \mu \mathrm{m}$

Figure 5: NLC Q10 penetration depth at various lipid compositions at $5^{\text {th }}$ hour.

Result of penetration depth test at $7^{\text {th }}$ hour
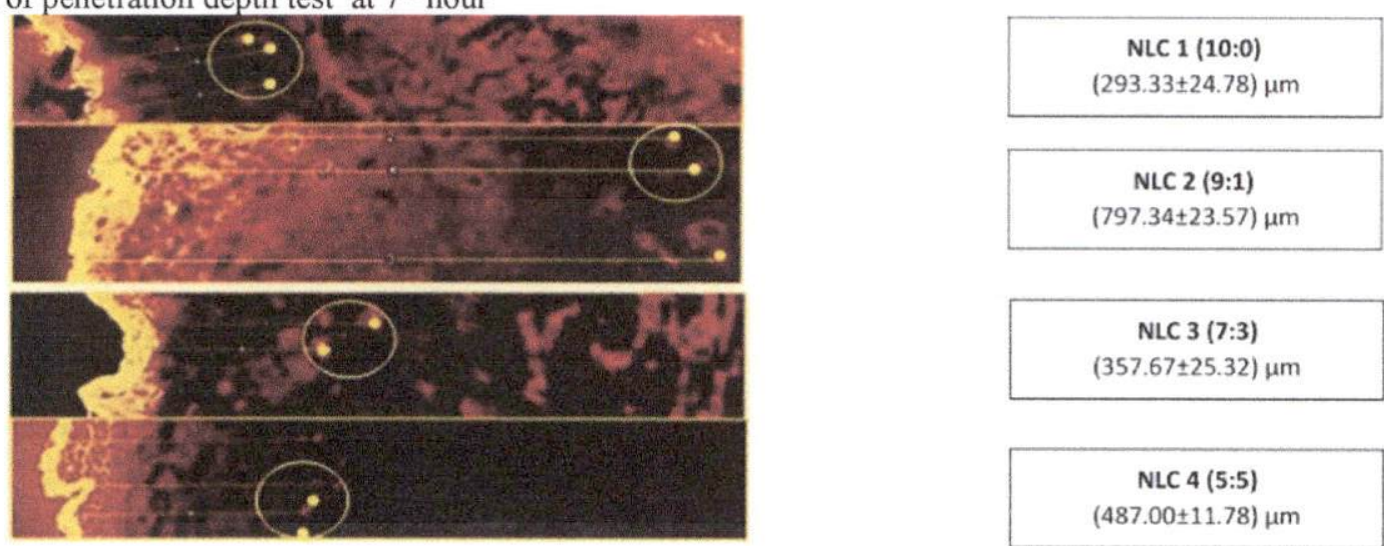

Figure 6: NLC Q10 penetration depth at various lipid compositions at $7^{\text {th }}$ hour.

matrix therefore the properties of the pure Q10 structure could not be observed ${ }^{15,16}$. From those figures can be seen that the appearance of diffraction angle between NLC systems with different lipid compositions showed no significant difference.

Entrappment Efficiency (EE)

The test results of NLC formulas can be seen in Table 3 . Based on the ANOVA statistical analysis results, EE of NLC Q10 system obtained p-value (sig) lowers than 0.05 . It showed that there was significant difference of EE between all NLC formulas at various lipid compositions, whereas NLC 4 has the best EE than any other systens.

Particle Morphology Test

The Test result of NLC Q10 particle morphology can be seen in figure 3 .

From particle morphology test in Figure 3 can be seen that the SLN Q10 (NLC 1) has less spherical shape compared with other NLC. NLC 2, 3 and 4 did not show significant morphological differences with same spherical shape with smaller size than NLC 1, but it can be seen that the NLC 3 shape (Formula NLC Q10 with the ratio of lipid solid: 
Penetration depth comparison of NLC preparation.

Below is the depth of penetration comparison from various NLC Q10 systems with various different lipid composition.

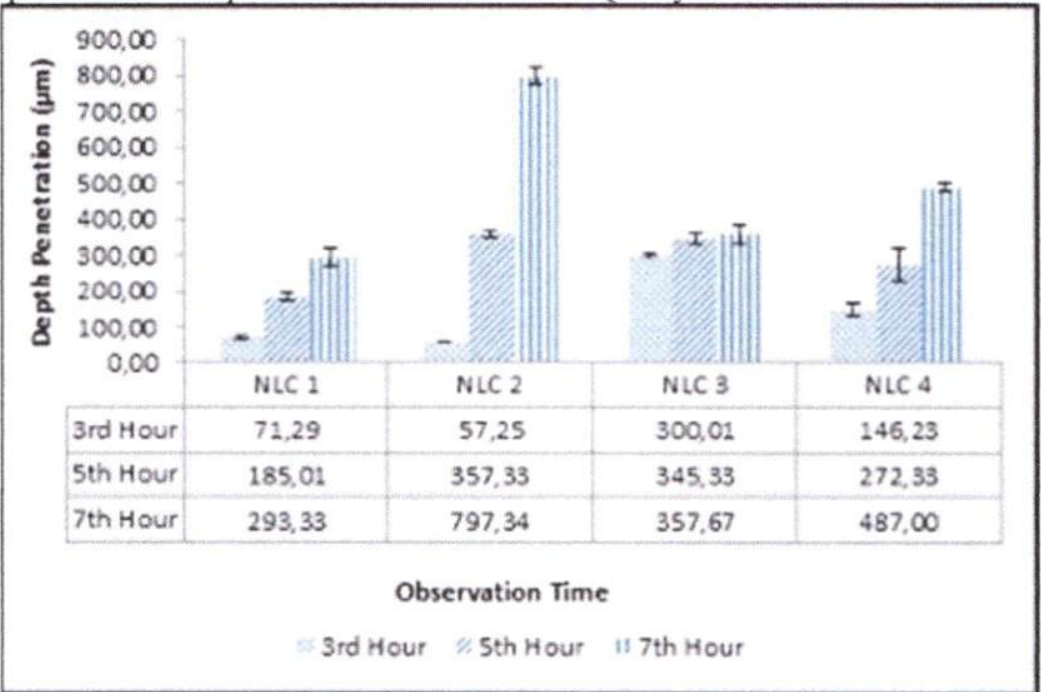

Figure 7: Penetration depth comparison of NLC Q10 with various lipid compositions at each observation hour

Qualitative intensity comparison of NLCQ10 penetration with various lipid compositions at each observation hour

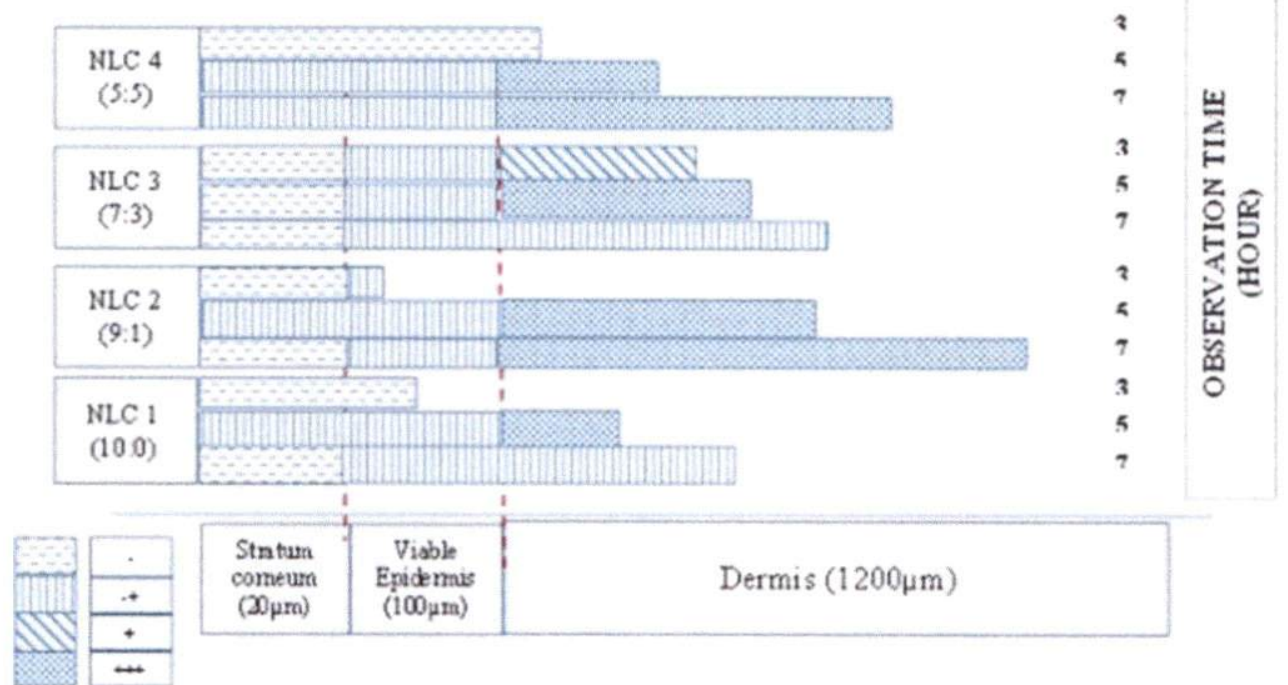

Figure 8: Qualitative intensity comparison of NLCQ10 penetration with various lipid compositions at each observation hour.

Table 4: Macrophages and fibroblasts amount from NLC Q10 observations at various lipid compositions.

\begin{tabular}{lll}
\hline Formula & $\begin{array}{l}\text { Total } \\
\text { Macrophages }\end{array}$ & Total Fibroblast \\
\hline NLC 1 & $46.00 \pm 6.48$ & $13.33 \pm 4.03$ \\
NLC 2 & $23.33 \pm 2.05$ & $19.33 \pm 3.09$ \\
NLC 3 & $25.67 \pm 8.34$ & $22.67 \pm 2.87$ \\
NLC 4 & $25.00 \pm 4.97$ & $\begin{array}{l}\text { No appearance of } \\
\text { fibroblast - PMN cell } \\
\end{array}$ \\
& & $( \pm 52)$ \\
\hline
\end{tabular}

liquid lipid $=7: 3$ ) was the most spherical particle compared to other formulas. They reported that morphologies and particle sizes were greatly influenced by oil concentration. They showed that increasing oil up to $30 \%$ produce spherical particles with smooth surfaces and small sizes ${ }^{21}$. Moreover, the micrograph also revealed the agglomeration of nanoparticles which might be due to the lipid nature of the carrier and the drying process during sample preparation prior to SEM analysis ${ }^{22,23}$. In summary, with the increasing concentration of liquid lipid, the formed particles become more spherical with smoother surfaces ${ }^{10}$

Penetration Test Results of Q10 at Rat Skin membranes Test results of penetration depth from NLC Q10 at various composition as follows:

From Figure 7 and 8 above can be seen that at $3^{\text {rd }}$ hour, NLC 3 and NLC 4 showed deeper penetration than other NLC systems. At the $5^{\text {th }}$ hour, all NLC systems showed significant increase in penetration depth. At the $7^{\text {th }}$ hour, all systems still showed increase in penetration depth, but 


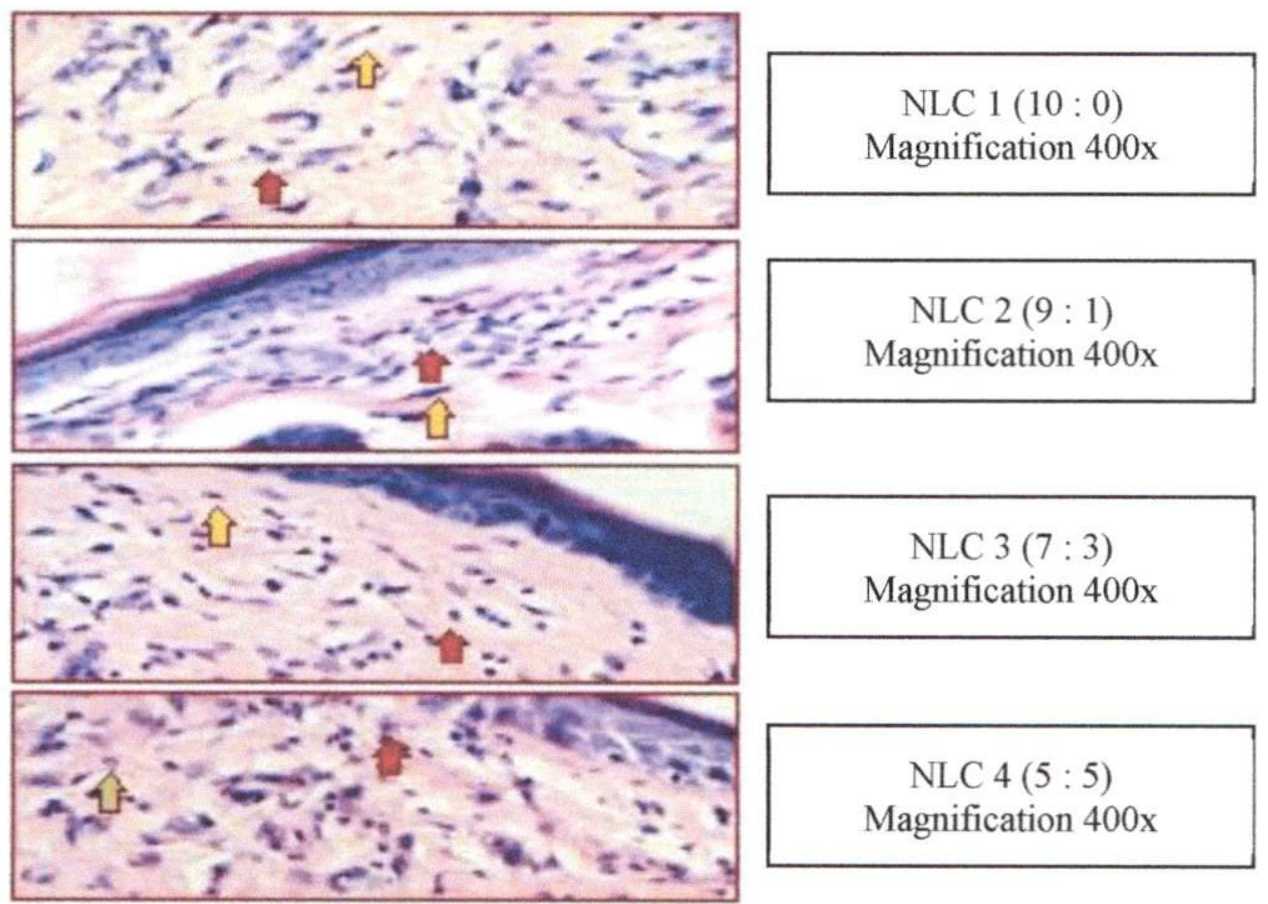

Yellow : Fibroblast
Red : Macrophage
Green : PMN Cell

Figure 9: Comparison of macrophage and fibroblast amount after 5 days treatment.

Table 6: Scoring amount of collagen density from effectiveness observation of NLC Q10 preparation at various lipid compositions.

\begin{tabular}{cc}
\hline NLC System & Scoring \\
\hline NLC 1 & 1 \\
NLC 2 & 4 \\
NLC 3 & 2 \\
NLC 4 & 0 \\
\hline
\end{tabular}

the most optimal penetration depth was NLC 2, the NLC Q10 system with lipid composition ratio of 9: 1. In summary, the NLC-based systems led to deeper skin penetration of both lipophilic model drugs ${ }^{19}$. Slower drug release profile of NLCs may increase the drug effect and durability on active site ${ }^{20}$

Effectiveness Test of NLC Q10 Preparation

Observations results of total macrophages, total fibroblasts and total collagen amount qualitatively

Observation of Total Macrophage and fibroblast

Functionally, the macrophages actively remove dead and damaged cells, bacteria and cellular debris from the body. Macrophage amount showed higher damaged / dead cells that exist on the skin, in this study, which is caused by UV exposure ${ }^{13}$. Otherwise, fibroblasts amount indicated that cell repair initiated by the use of NLC with various lipid compositions after being exposed to UV. From Table 4 it can be seen that after 5 days treatment, NLC 2 showed macrophages amount were lower than other NLC systems, while NLC 3 showed higher fibroblast amount than other NLC systems. From this observation, it can be concluded that NLC 2 and NLC 3 could provide better cellular repair after being exposed.

Statistical analysis from both macrophages and fibrobast amount showed that p-value (sig) was less than 0.05 . This showed there were significant differences in macrophage and fibroblast amount which were formed after treatment. Collagen amount observation

Collagen amount was determined based on hispatological parameters score in the calculation of several field of view at $400 \mathrm{x}$ magnification as seen in table below

The observation results of collagen density from NLC preparation at various lipid compositions is:

From table 6, it can be seen that after 5 days treatment, NLC 2 showed high scoring of collagen density qualitatively compared to other systems. Initial formation of collagen fibers showed sustained improvement after the formation of fibroblast cells. It can be concluded that the NLC 2 showed better cell repair compared to other systems. The initial rapid release of Q10-loaded NLCs may be caused by the enrichment of Q10 in the outer surface of the NLCs that immediately diffuses into the release medium. The later sustained release could be attributed to the degradation and erosion of the inner lipid matrix where the drug could be molecularly dispersed or dissolved ${ }^{24}$ From the EE value, it can be seen that NLC 2 had low value but it gave good effectiveness. This was because the smaller EE value, the more active ingredient in the outer system and not in entrapped condition. It allows active ingredient to penetrate deeper and gave better 

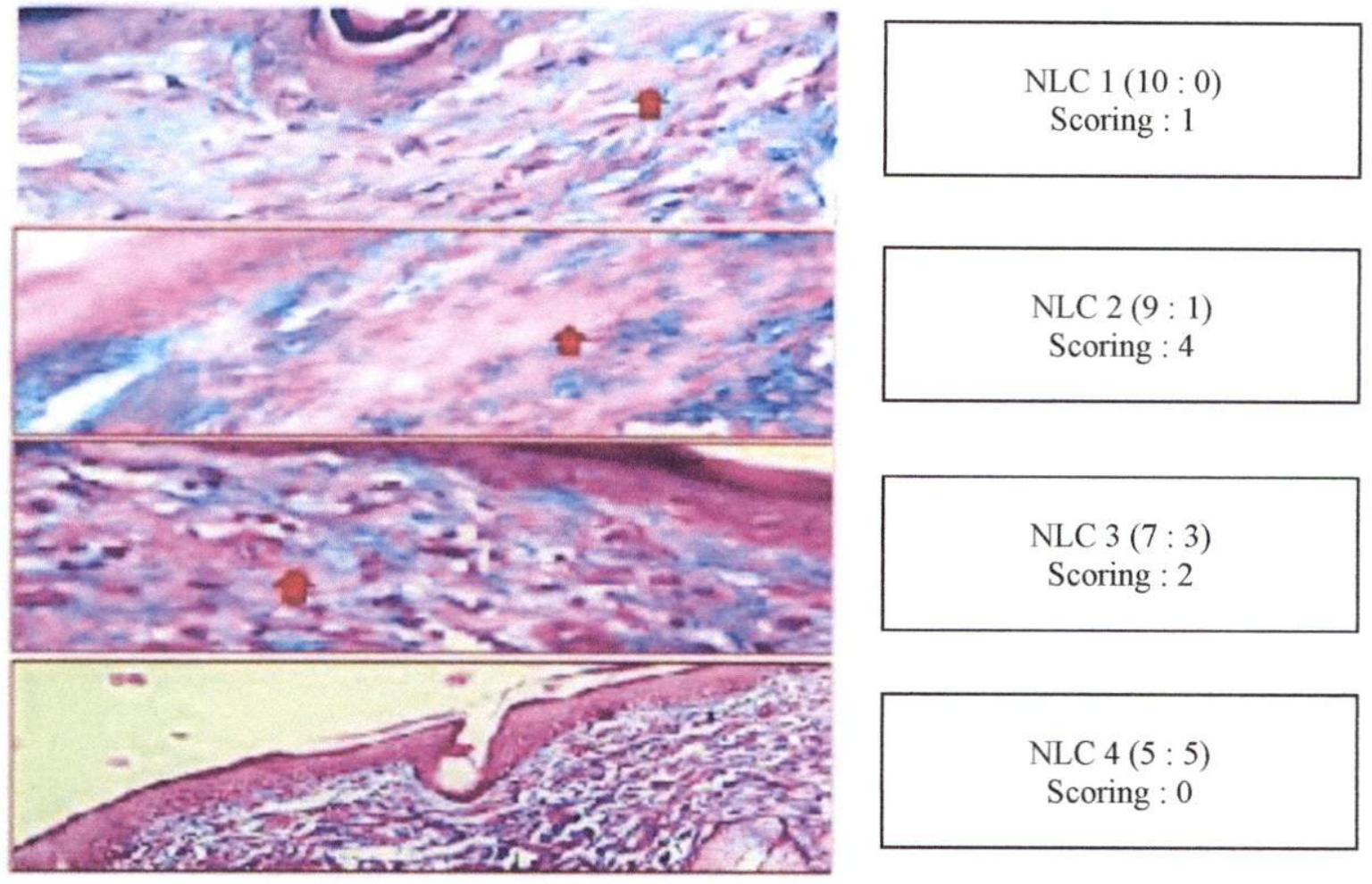

Figure 10: Collagen density comparison after 5 days treatment.

Table 5: Histopatological scoring parameters for collagen density.

\begin{tabular}{|c|c|}
\hline Scoring & Parameters \\
\hline 0 & There was no collagen appearance \\
\hline+1 & $\begin{array}{l}\text { The collagen density was low } \\
\text { (approximately } 10 \% \text { per field of view) }\end{array}$ \\
\hline+2 & $\begin{array}{l}\text { The collagen density was moderate } \\
(10 \mathrm{~s} / \mathrm{d} 50 \% \text { per field of view) }\end{array}$ \\
\hline+3 & $\begin{array}{l}\text { The density of collagen is dense } \\
(50 \mathrm{~s} / \mathrm{d} 90 \% \text { per field of view) }\end{array}$ \\
\hline+4 & $\begin{array}{l}\text { The density of collagen is very dense } \\
(90 \mathrm{~s} / \mathrm{d} 100 \% \text { per field of view) }\end{array}$ \\
\hline
\end{tabular}

effect. Further more, the entrapped active ingredient served as reservoir that can maintain drug levels.

\section{CONCLUSION}

From this research can be concluded that lipid composition affected the NLC characteristics, Q10 penetration and effectiveness of Q10 as antioxidant, NLC $2(9: 1)$ was the most optimal lipid composition to increase the penetration and Q10 effectiveness as antioxidant in anti-aging cosmetics.

\section{REFERENCES}

1. Dayan, N. (2008). Skin aging handbook. NewYork: William Andrew. p. 16-21; p. 56-68

2. Muta-Takada, K., Terada, T., Yamanishi, H., Ashida, Y., Inomata, S., Nishiyama, T., \& Amano, S. (2009). Coenzyme Q10 protects against oxidative stressinduced cell death and enhances the synthesis of basement membrane components in dermal and epidermal cells. Biofactors, 35(5), 435-441.

3. Hoppe, U., Bergemann, J., Diembeck, W., Ennen, J., Gohla, S., Harris, I., \& Steckel, F. (1999). Coenzyme Q10, a cutaneous antioxidant and energizer. Biofactors-Oxford Then Amsterdam, 9, p. 371-378.

4. Zhang, M., Dang, L., Guo, F., Wang, X., Zhao, W., \& Zhao, R. (2012). Coenzyme Q10 enhances dermal elastin expression, inhibits $\mathrm{IL}-1 \alpha$ production and melanin synthesis in vitro. International journal of cosmetic science, 34(3), p. 273-279

5. Inui, M., Ooe, M., Fujii, K., Matsunaka, H., Yoshida, M., \& Ichihashi, M. (2008). Mechanisms of inhibitory effects of CoQ10 on UVB-induced wrinkle formation in vitro and in vivo. Biofactors, 32(1-4), p. 237-243.

6. Müller, R. H., Petersen, R. D., Hommoss, A., \& Pardeike, J. (2007). Nanostructured lipid carriers (NLC) in cosmetic dermal products. Advanced Drug Delivery Reviews, 59(6), 522-530.

7. Chen, S., Liu, W., Wan, J., Cheng, X., Gu, C., Zhou, H., \& Yang, X. (2013). Preparation of Coenzyme Q10 nanostructured lipid carriers for epidermal targeting with high-pressure microfluid

8. Aqilah, S., Hendradi, Esti., Rosita, Noorma., (2016). Effect of Solid Lipid Nanoparticle (SLN) and Nanostructured Lipid Carrier (NLC) on Antioxidant Stability of Tomato Extract (Lipid : Cetyl Alcohol and Isopropyl Myristate) in Interprofessional Collaboration to Achieve Sustainable Development Goals (SDGs). University of Jember.

9. Loo, C. H., Basri, M., Ismail, R., Lau, H. L. N., Tejo, B. A., Kanthimathi, M. S., \& Choo, Y. M. (2013). 
Effect of compositions in nanostructured lipid carriers (NLC) on skin hydration and occlusion. International journal of nanomedicine, 8 ; p. 13-22

10. Hu, F. Q., Jiang, S. P., Du, Y. Z., Yuan, H., Ye, Y. Q., \& Zeng, S. (2005). Preparation and characterization of stearic acid nanostructured lipid carriers by solvent diffusion method in an aqueous system. Colloids and Surfaces B: Biointerfaces, 45(3), 167-173

11. Jenning, V., Thünemann, A. F., \& Gohla, S. H. (2000). Characterisation of a novel solid lipid nanoparticle carrier system based on binary mixtures of liquid and solid lipids. International Journal of Pharmaceutics, 199(2), 167-177.

12. Souto, E. B., Doktorovova, S., Gonzalez-Mira, E., Egea, M. A., \& Garcia, M. L. (2010). Feasibility of lipid nanoparticles for ocular delivery of antiinflammatory drugs. Current eye research, 35(7), 537552.

13. Triyono, B, 2005. Different Appearance of Collagen around Incision Wound at Wistar Rat Which Given With Pain Reliever of Levobupikain and No Levobupikain. University of Diponegoro. Semarang

14. Wu, P. S., Lin, C. H., Kuo, Y. C., \& Lin, C. C. (2017). Formulation and characterization of hydroquinone nanostructured lipid carriers by homogenization emulsification

Nanomaterials, 2017.

15. Orgul, D., Eroglu, H., \& Hekimoglu, S. (2017) Formulation and characterization of tissue scaffolds containing simvastatin loaded nanostructured lipid carriers for treatment of diabetic wounds. Journal of Drug Delivery Science and Technology, 41, 280-292.

16. M. Gambhire, M. Bhalekar, B. Shrivastava, Bioavailability assessment of simvastatin loaded solid lipid nanoparticles after oral administration, Asian Journal of Pharmaceutical Sciences, 6 (2011) 251-258

17. Malik, D. S., \& Kaur, G. (2018). Nanostructured gel for topical delivery of azelaic acid: Designing, characterization, and in-vitro evaluation. Journal of Drug Delivery Science and Technology, 47, 123-136.

18. J. Pardeike, S. Weber, T. Haber, J. Wagner, H.P. Zarfl, H. Plank, A. Zimmer, Development of an itraconazoleloaded nanostructured lipid carrier (NLC) formulation for pulmonary application. Int. J. Pharm. 419 (2011) 329-338

19. Wolf, M., Reiter, F., Heuser, T., Kotisch, H., Klang, V., \& Valenta, C. (2018). Monoacyl-phospatidylcholine based drug delivery systems for lipophilic drugs: Nanostructured lipid carriers vs. nano-sized emulsions. Journal of Drug Delivery Science and Technology.

20. J.E. Nazhad Dolatabadi, A. Azami, A. Mohammadi, H. Hamishehkar, V. Panahi-Azar, Y.R. Saadat, A.A. Saei, Formulation, characterization and cytotoxicity evaluation of ketotifen-loaded nanostructured lipid carriers, Journal of Drug Delivery Science and Technology (2018), doi: 10.1016/j.jddst.2018.05.017

21. Babazadeh, B. Ghanbarzadeh, H. Hamishehkar, Formulation of food grade nanostructured lipid carrier (NLC) for potential applications in medicinal-functional foods, Journal of Drug Delivery Science and Technology (2017), doi: 10.1016/j.jddst.2017.03.001

22. Bose, S.; Michniak-Kohn, B. Preparation and characterization of lipid based nanosystems 506 for topical delivery of quercetin. European Journal of Pharmaceutical Sciences. 2013, 48, 507 442-452

23. Babazadeh, A., Ghanbarzadeh, B., \& Hamishehkar, H. (2017). Formulation of food grade nanostructured lipid carrier (NLC) for potential applications in medicinalfunctional foods. Journal of Drug Delivery Science and Technology, 39, 50-58,

24. Lee, S. G., Kim, C. H., Sung, S. W., Lee, E. S., Goh, M. S., Yoon, H. Y., \& Choi, Y. W. (2018). rIPl peptideconjugated nanostructured lipid carriers for enhanced intracellular drug delivery to hepsin-expressing cancer cells. International journal of nanomedicine, 13, 3263. 
Help

About Us

\title{
International Journal of Drug Delivery Technology
}

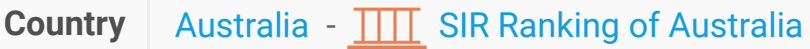 \\ Subject Area and \\ Category \\ Publisher International Journal of Drug Delivery Technology \\ Publication type Journals \\ ISSN 09754415 \\ Coverage 2011-ongoing \\ Scope International Journal of Drug Delivery Technology (IJDDT) provides the forum for reporting \\ innovations, production methods, technologies, initiatives and the application of scientific \\ knowledge to the aspects of pharmaceutics, including controlled drug release systems, drug \\ targeting etc. in the form of expert forums, reviews, full research papers, and short \\ communications. \\ Homepage \\ How to publish in this journal \\ Contact \\ Join the conversation about this journal

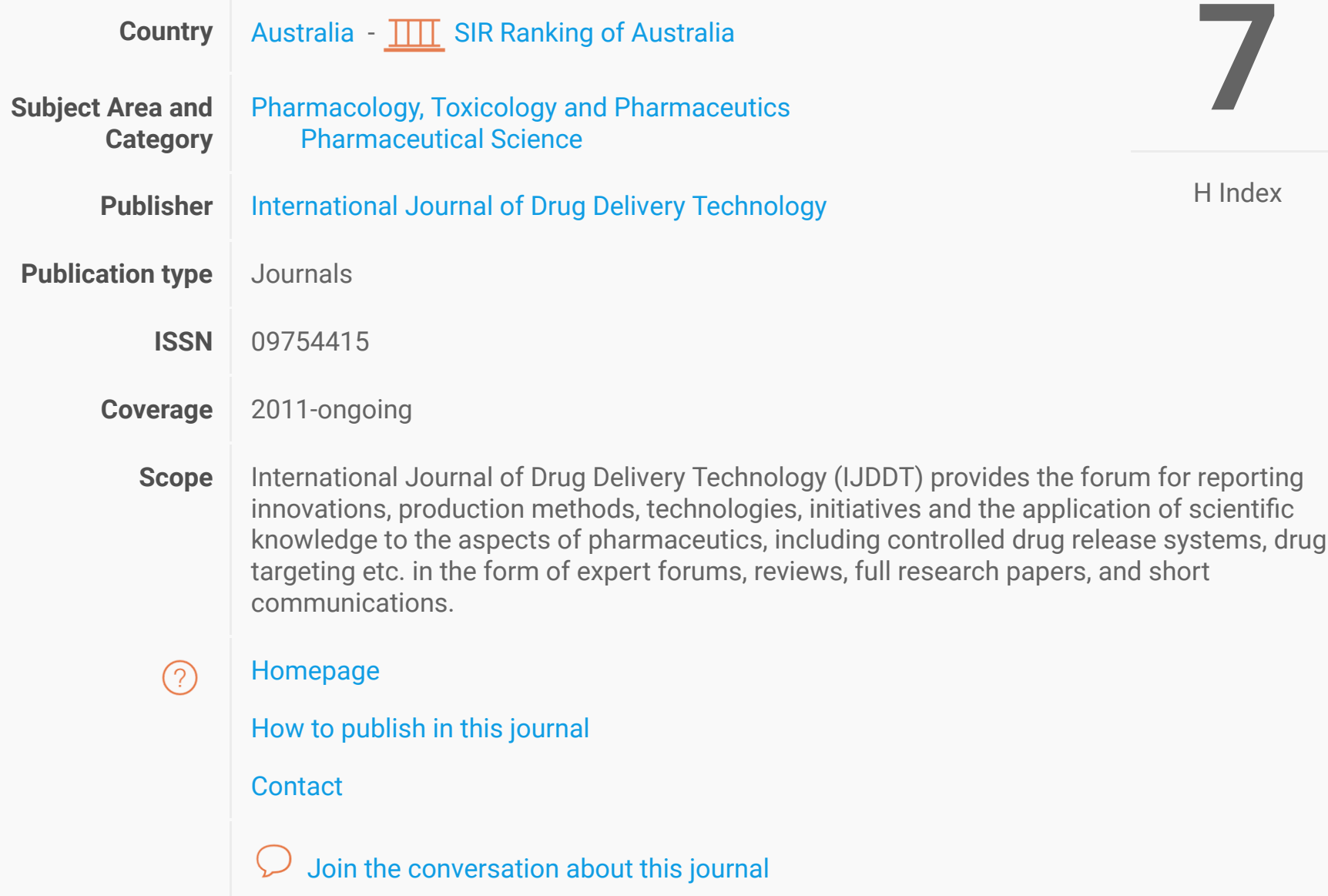

\section{Quartiles}

Pharmaceutical Science
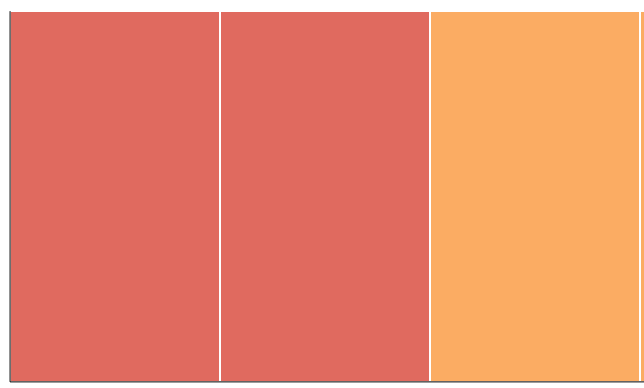


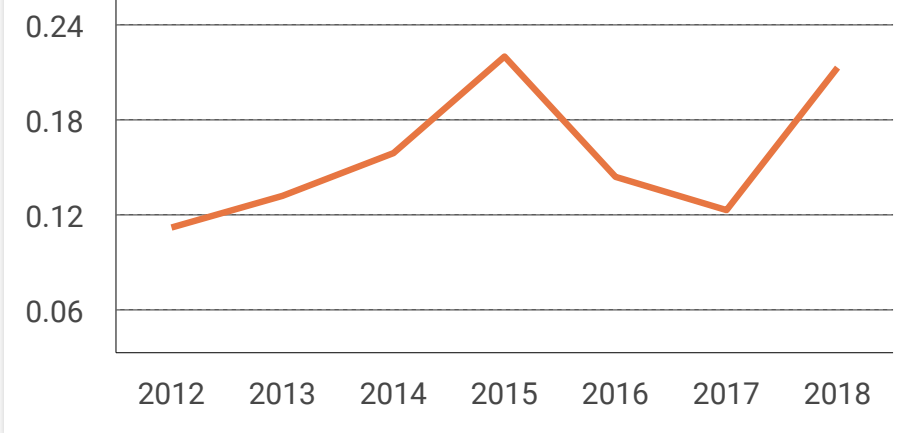

Total Cites Self-Cites +

40

20

0

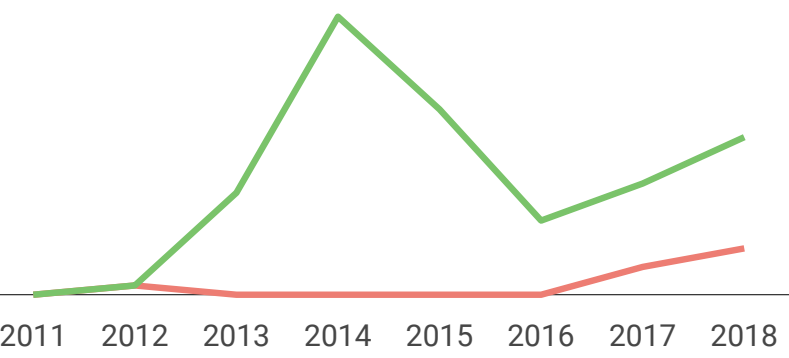

External Cites per Doc Cites per Doc

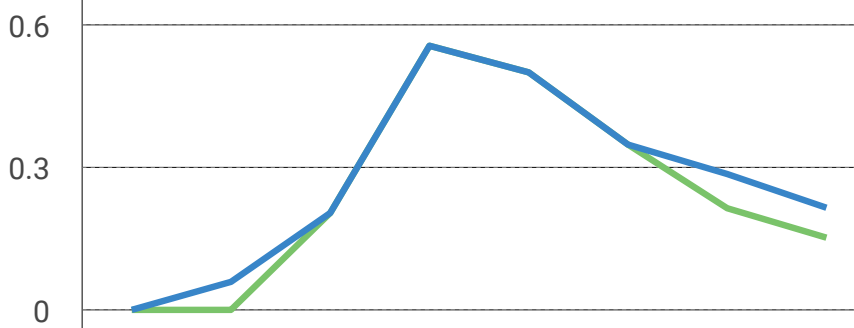

$\begin{array}{llllllll}2011 & 2012 & 2013 & 2014 & 2015 & 2016 & 2017 & 2018\end{array}$

Citable documents Non-citable documents + 80

40

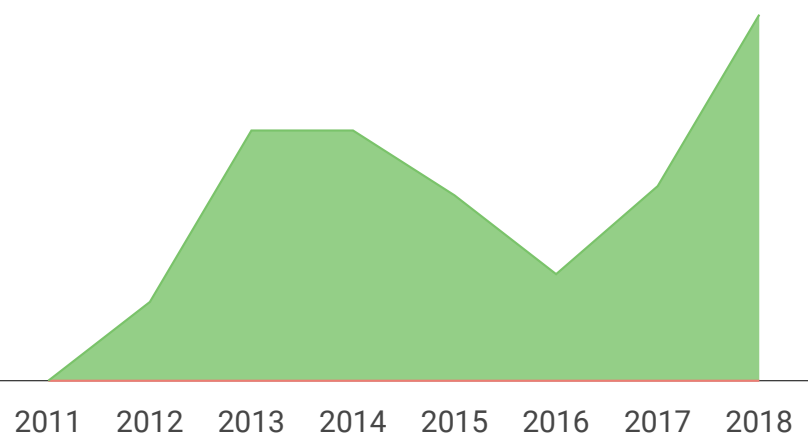

Show this widget in your own website

Just copy the code below
0.6

0.4

0.2

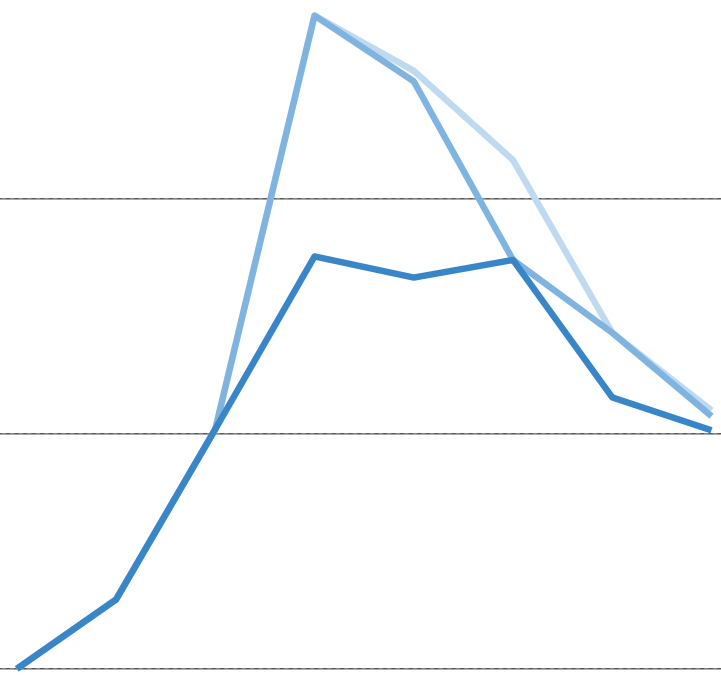

$\begin{array}{llllllll}2011 & 2012 & 2013 & 2014 & 2015 & 2016 & 2017 & 2018\end{array}$

Cites / Doc. (4 years)

Cites / Doc. (3 years)

Cites / Doc. (2 years)

$\%$ International Collaboration

40

20

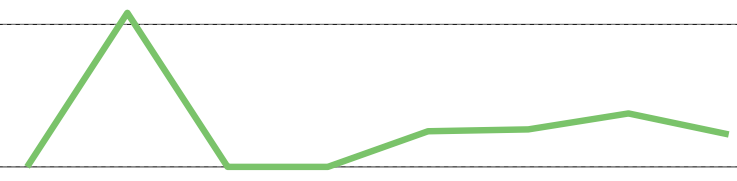

$\begin{array}{llllllll}2011 & 2012 & 2013 & 2014 & 2015 & 2016 & 2017 & 2018\end{array}$

Cited documents Uncited documents $+$

80

40

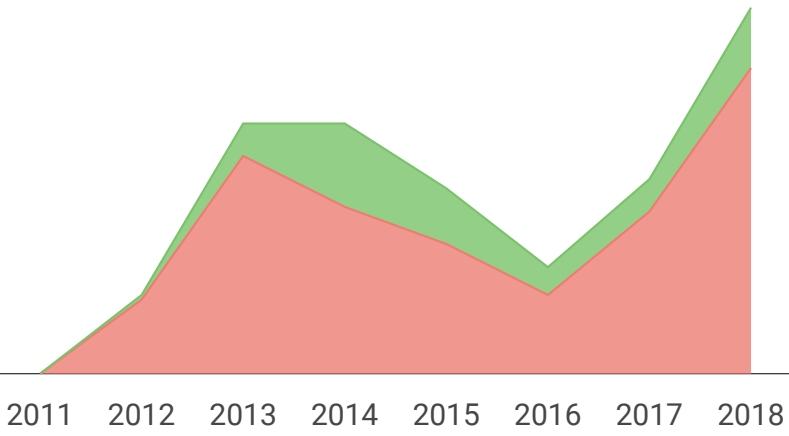




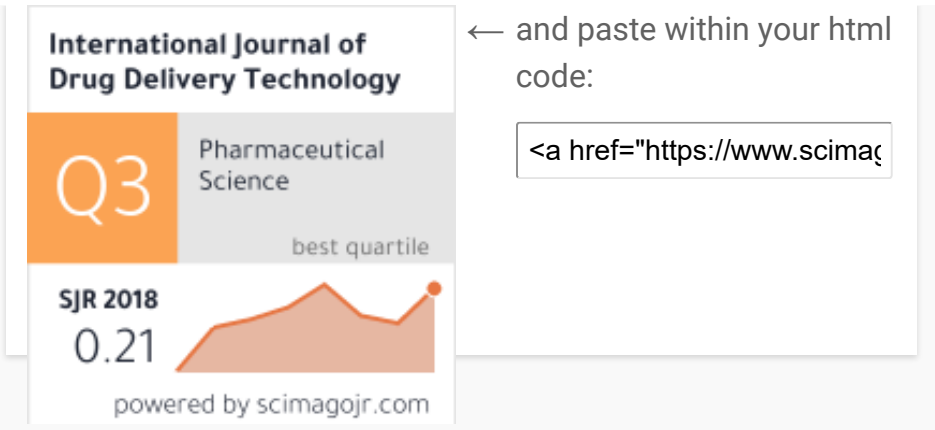

\section{R Rajaa abbas 4 weeks ago}

Hi sir :

I'd like to publish my paper in your journal

My name is Rajaa abbas and I'm a pharmacist with master degree .

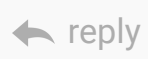

\section{Melanie Ortiz 4 weeks ago}

Dear Rajaa, thank you very much for your comment. Sorry to tell you that SCImago Journal \& Country Rank is not a journal. SJR is a portal with scientometric indicators of journals indexed in Elsevier/Scopus. We suggest you to look for author's instructions/submission guidelines in the journal's website. Best Regards, SCImago Team

\section{A Assistent prof .dr.saba hadee 3 months ago}

Dear editor

I would like to publish my paper in your journal, please could you tell me weither you accept aresearch paper from Iraq /University of baghdad /College of pharmacy and Iwant to asked about the processing fee of your journal.

With my best regard

\& reply 